\title{
Study rationale and protocol: prospective randomized comparison of metal ion concentrations in the patient's plasma after implantation of coated and uncoated total knee prostheses
}

\author{
Jörg Lützner*1, Gerd Dinnebier ${ }^{2}$, Albrecht Hartmann ${ }^{1}$, Klaus-Peter Günther ${ }^{1}$ \\ and Stephan Kirschner ${ }^{1}$
}

\begin{abstract}
Address: ${ }^{1}$ Department of Orthopaedic Surgery, University Hospital Carl Gustav Carus, Medical Faculty of the Technical University of Dresden, Germany and 2Institute of Clinical Chemistry and Laboratory Medicine, University Hospital Carl Gustav Carus, Medical Faculty of the Technical University of Dresden, Germany

Email: Jörg Lützner* - Joerg.Luetzner@uniklinikum-dresden.de; Gerd Dinnebier - Gerd.Dinnebier@uniklinikum-dresden.de; Albrecht Hartmann - Albrecht.Hartmann@uniklinikum-dresden.de; Klaus-Peter Günther - Klaus-Peter.Guenther@uniklinikum-dresden.de; Stephan Kirschner - Stephan.Kirschner@uniklinikum-dresden.de

* Corresponding author
\end{abstract}

Published: 14 October 2009

BMC Musculoskeletal Disorders 2009, 10:128 doi:10.1 I86/147/-2474-10-128

This article is available from: http://www.biomedcentral.com/I47/-2474/10/128

(c) 2009 Lützner et al; licensee BioMed Central Ltd.

This is an Open Access article distributed under the terms of the Creative Commons Attribution License (http://creativecommons.org/licenses/by/2.0), which permits unrestricted use, distribution, and reproduction in any medium, provided the original work is properly cited.
Received: 3 July 2009

Accepted: 14 October 2009

\begin{abstract}
Background: Any metal placed in a biological environment undergoes corrosion. Thus, with their large metallic surfaces, TKA implants are particularly prone to corrosion with subsequent release of metal ions into the human body which may cause local and systemic toxic effects and hypersensitivity reactions, and increase cancer risk. To address this problem, a new 7-layer zirconium coating developed especially for cobalt-chrome orthopaedic implants was tested biomechanically and found to lower metal ion release.
\end{abstract}

The purpose of the proposed clinical trial is to compare the metal ion concentration in patients' plasma before and after implantation of a coated or uncoated TKA implant.

Methods/Design: In this randomised controlled trial, 120 patients undergoing primary TKA will be recruited at the Department of Orthopaedic Surgery of the University Hospital in Dresden, Germany, and randomised to either the coated or uncoated prosthesis. Outcome assessments will be conducted preoperatively and at 3 months, 12 months and 5 years postoperatively. The primary clinical endpoint will be the chromium ion concentration in the patient's plasma after I and 5 years. Secondary outcomes include cobalt, molybdenum and nickel ion concentrations after I and 5 years, allergy testing for hypersensitivity against one of these metals, the Knee Society Score to assess clinical and physical function of the knee joint, the self-assessment Oxford Score and the Short Form 36 quality of live questionnaire.

Discussion: The metal ion concentration in the patient's plasma has been shown to increase after TKA, its eventual adverse effects being widely debated. In the light of this discussion, ways to reduce metal ion release from orthopaedic implants should be studied in detail. The results of this investigation may lead to a new method to achieve this goal.

Trials register: Clinicaltrials registry NCT008625 I I 


\section{Background}

Total knee arthroplasty (TKA) is a very successful treatment option for advanced osteoarthritis of the knee with about 146.000 operations performed in 2008 in Germany [1]. Although patients obviously benefit from joint replacement in terms of mobility and quality of life, implant-specific local and systemic adverse effects, due to corrosion and wear, still constitute a matter of concern [2$6]$. Besides polyethylene wear which is one cause for aseptic loosening, metal ion release from metallic implants is also subject of debate. Every metal implant in a biological environment corrodes, depending on the exposed surface area and the composition of the alloy [7]. This process results in the release of metal ions.

It has been suggested that metal ion release may trigger local and systemic toxic effects [8] and hypersensitivity reactions [9-12]. Furthermore, in animal studies, cobalt and chromium ion exposure was found to have carcinogenic and mutagenic effects. Therefore, cancer risk may increase from exposure to the cobalt and chromium ions released by metal implants [13-15]. In contrast to these experimental data, epidemiologic studies did not find a greater risk of developing a malignancy after TKA $[6,16,17]$. However, increases in lymphoma, cancer of the endometriuma and prostate and skin melanoma were observed that could be related to TKA $[16,17]$.

As they contain large metallic surfaces, TKA implants are particularly subject to corrosion inducing release of metal ions. Significantly higher metal ion concentrations were detected in patients after TKA compared to patients without metal implants [18]. Attempts have been made to reduce metal ion release and to improve the tribological properties of TKA implants by coating the chrome-cobalt body with various zirconium compositions, especially designed for patients with metal hypersensitivity. In invitro biomechnical tests, they showed superior tribological characteristics and thus less polyethylene wear particles [19-22]. However, in clinical tests, they presented early radiolucent lines [23] and achieved less favourable results in the Australian TKA registry [24].

To reduce ion release, a new multilayer coating system was developed consisting of a thin adhesive chrome layer, five alternating intermediate layers out of chrome nitride (CrN)-chrome carbonitride ( $\mathrm{CrCN}$ ) and a final shielding zirconium nitride $(\mathrm{ZrN})$ layer.

The 7-layer coating system is applied on the CoCrMo knee implants through the chemical vapour deposition (CVD) method with a total thickness of about 3,5 to $6 \mu \mathrm{m}$. The gradiently applied $\mathrm{CrN}-\mathrm{CrCN}$ layers allow to bridge the difference in hardness and tension between the softer material CoCrMo and the very hard $\mathrm{ZrN}$ shielding layer and thus ensure the system's mechanical integrity. The interfaces between the layers constitute an additional diffusion barrier against ions from the base material. In addition, the final ceramic $\mathrm{ZrN}$ layer seals the system and is highly biocompatible.

To evaluate its abrasive properties, it was tested in an invitro simulation according to ISO 14243-1:2002(E) through 5 million cycles with a frequency of $1 \mathrm{~Hz}$.

Nickel and molybdenum ion release of the $\mathrm{ZrN}$-coated implants into the wear test serum was reduced to the point that traces of these elements were found only within the range of detection levels while only minimal traces of cobalt and chrome were detected in the test serums, inferior by orders of magnitude to those of the uncoated implants out of CoCrMo [25].

Therefore, this surface coating could help to significantly reduce release of metal ions in TKA patients.

The aim of this study is to compare this novel surface coating with the standard CrCoMb-alloy in terms of metal ion levels in patients' plasma, metal hypersensitivity and clinical and radiological results.

\section{Study Hypothesis}

The study's hypothesis is that metal ion concentrations in the patient's plasma will be significantly lower in the group receiving the $\mathrm{ZrN}$-coated implant than in the other group.

\section{Methods/Design}

This study is a single-centre randomised controlled trial that will be conducted at the Medical Faculty of the Technical University of Dresden. The study protocol was approved by the local independent Ethics Committee in February 2009 and registered in the US National Institutes of Health's database http://www.clinicaltrials.gov registry under NCT00862511.

The trial is performed according to the guidelines for Good Clinical Practice (GCP), as applicable.

\section{Inclusion and Exclusion Criteria}

Potential participants will be screened and recruited the orthopaedic pre-admission clinic.

Inclusion criteria are: (i) indication for TKA in cases of primary or secondary osteoarthritis, (ii) written informed consent. Exclusion criteria include (i) metal implants or endoprostheses, (ii) hypersensitivity against metals or bone cement particles, (iii) any form of malignancies, (iiii) renal insufficiency, (iiiii) other severe illnesses that would impair participation in this study. All eligible 
patients will be asked whether they are willing to participate in the trial and, if so, required to provide a written informed consent. They will be informed about the purpose of the trial, the operative procedures as well as their options and risks. They will be randomised to either a coated or uncoated TKA implant (Columbus, Aesculap, Tuttlingen, Germany, see figure 1 \& 2) using a randomisation list.

\section{Operative Procedure}

In all cases, the coated or uncoated model of a cemented unconstrained total knee prosthesis with a fixed polyethylene insert is implanted. Both implants are CE-certified.

All operations are performed with a tourniquet after a single dose of antibiotics (1.5 g Cefuroxim), using a medial parapatellar approach with a femur-first preparation.

Femoral alignment in the frontal plane is is directed at an angle of $90^{\circ}$ to the mechanical axis in the frontal plane. For sagittal alignment, it is placed parallel to the ventral femoral cortex and, for rotational alignment, parallel to

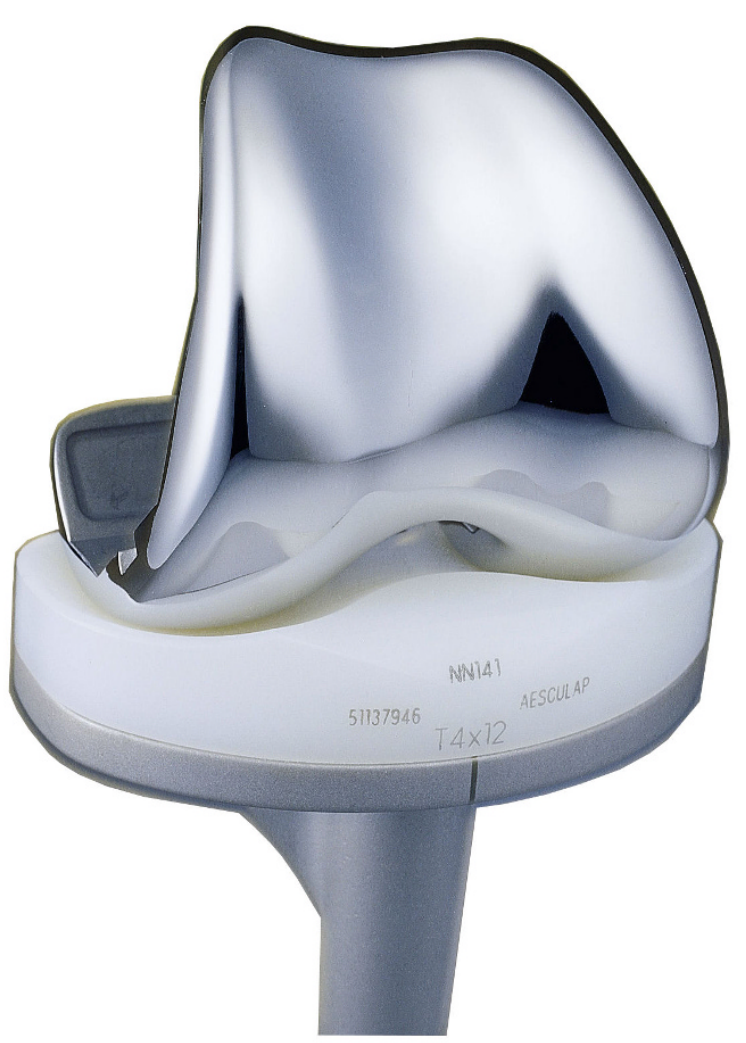

Figure I

View of the Columbus knee system (Aesculap, Tuttlingen, Germany).

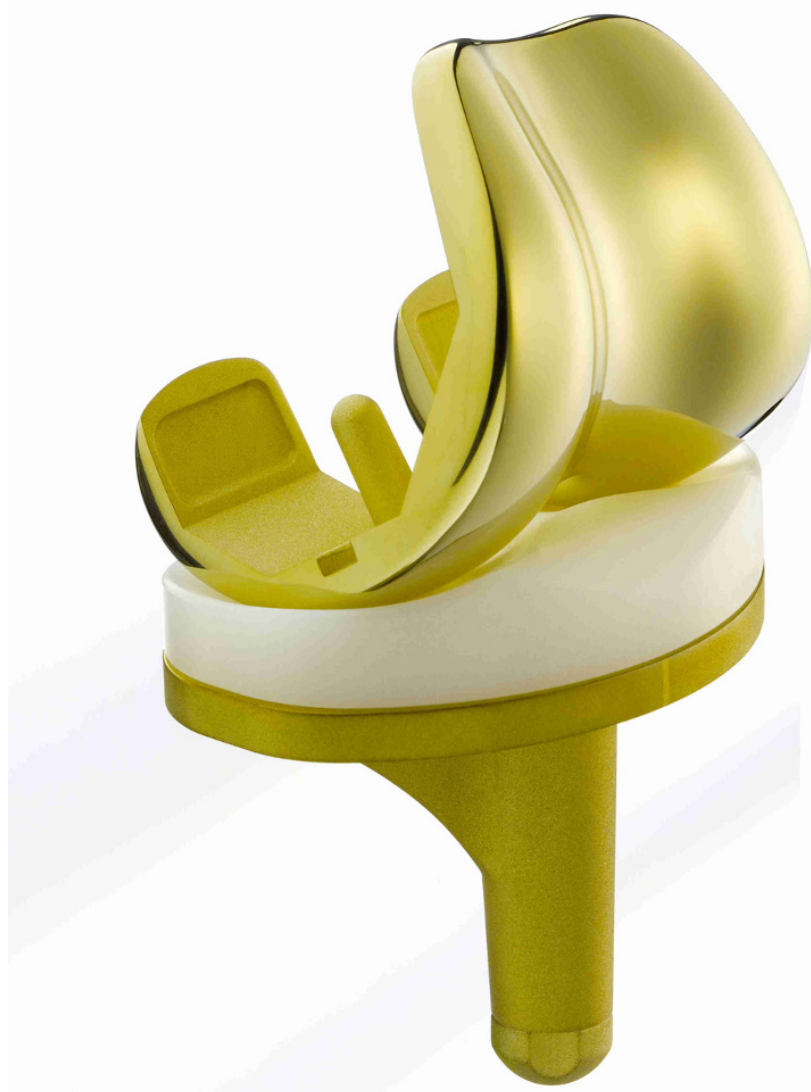

\section{Figure 2 \\ View of the the ZrN-coated Columbus AS knee sys- tem (Aesculap, Tuttlingen, Germany).}

the transepicondylar axis. Tibial alignment is directed at an angle of $90^{\circ}$ to the mechanical axis in the frontal plane, with a $5^{\circ}$ posterior slope in the sagittal plane and at the medial third of the tibial tubercle for rotational alignment. Postoperatively full weight-bearing is allowed, and mobilisation starts from the first postoperative day.

\section{Clinical Endpoints}

The primary endpoint of this investigation is the difference in chromium ion concentration in the patient's plasma after 1 and 5 years. Secondary endpoints are the differences in cobalt, molybdenum and nickel ion concentration after 1 and 5 years and a possible hypersensitivity against one of these metals after 1 year postoperatively.

The metal ion concentrations are to be analysed for a potential correlation to biomechanical factors (BMI, mechanical axis), activity (UCLA), function (KSS) and quality of live (Oxford Score, SF 36). 
The patients will be clinically examined preoperatively and 3 months, 1 year and 5 years after surgery. They will be asked to complete the Knee Society score, the Oxford Knee score, the Short Form 36 and the UCLA activity score questionnaires. They will be tested for hypersensitivity against metal ions preoperatively and one year postoperatively. They will be contacted by phone 2, 3 and 4 years postoperatively and asked to complete the Oxford Knee score questionnaire. Adverse and serious adverse events will be evaluated according to Good Clinical Practice (see table 1 for details).

\section{Metal Ion Analysis}

Blood samples are collected in 7,5 ml S-Monovette ${ }^{\varpi}$ tubes (for trace metal analysis, Sarstedt AG, Germany) using a specific steel needle for trace metal analysis (Sarstedt AG, Germany). Within one hour, plasma is separated by centrifugation at $2000 \mathrm{~g}$ for $10 \mathrm{~min}$. Samples are stored at $20^{\circ} \mathrm{C}$ before being analysed for chromium, cobalt, molybdenum and nickel content using a graphite furnace atomic absorption spectrometer Z-8270 with Polarisation-Zeeman-Absorption (Hitachi Ltd., Japan) [26,27]. Calibration is performed by the standard addition method using $0.00 \mu \mathrm{g} / \mathrm{l}, 5.00 \mu \mathrm{g} / \mathrm{l}$ and $10.00 \mu \mathrm{g} / \mathrm{l}$ as calibration points in triplicate for each element. The samples are diluted $1: 2$ in buffer $\left(1 \% \mathrm{HNO}_{3}\right.$ [Merck AG, Germany], $0.2 \%$ Triton X-100 [SIGMA-Aldrich Chemie GmbH, Germany], 0.2\% Antifoam B [SIGMA-Aldrich Chemie $\mathrm{GmbH}$, Germany]; $\mathrm{Cr}$ and Co: additional $0.8 \%$ Pd-matrix-modifier [Merck AG, Germany], 0.3\% Mgmatrix-modifier [Merck AG, Germany]). The accuracy and precision of the method is validated to $<10 \%$ using the control materials Seronorm ${ }^{\mathrm{TM}}$ Trace Elements Serum (SERO AS, Norway). The detection limit of the method is estimated at $0.5 \mu \mathrm{g} / \mathrm{l}$ for each element (mean $+3 \mathrm{sd}$ from buffer). The Dixon test was used to eliminate aberrant values. All probes having ion levels below the detection levels are adjusted to $<0.25 \mu \mathrm{g} / \mathrm{l}$.

\section{Sample Size Considerations}

To estimate the number of cases, own data from a crosssectional study of patients with a CrCoMb alloy TKA was used [18]. The chromium ion concentration in the patient's plasma 5 to 7 years postoperatively was in average $0.92 \mu \mathrm{g} / \mathrm{l}$ (interquartile range $0.73-1.32 \mu \mathrm{g} / \mathrm{l}$ ). For the difference between an uncoated and a $\mathrm{ZrN}$-coated prosthesis, the data of a biomechanical study [25] was used. This in-vitro test demonstrated a 40 times higher chromium ion release in the uncoated implant. 3 coated and 3 uncoated implants were tested and the serum after 1 million loading cycles was taken for the measurement of metal ion concentration. The chromium ion concentrations was $201 \mu \mathrm{g} / \mathrm{l}$ for the uncoated implant and $4.5 \mu \mathrm{g} / \mathrm{l}$ for the coated implant.

Taking into account that a normal distribution of data can not be assumed, the relatively high age of the patients and an expected drop-out rate of $25 \%$, the necessary number of cases was estimated at 60 patients per group when a significance level of $5 \%$ and a test strength of $80 \%$ are required.

\section{Data Acquisition and Management}

Patients will be interviewed by a local study nurse preoperatively and at specified time intervals postoperatively (see table 1 for details). In addition to the written interview, the Knee Society score, the Oxford Knee score, the Short Form 36 and the UCLA activity score will be recorded.

Data will be entered in prepared CRFs and then transferred to a SPSS database and subjected to range and plausibility checks. Data reported on the CRF derived from source documents (e.g. operative report) should be consistent with the source documents or the discrepancies should be explained.

The clinical database, including all information until 5 years postoperatively, will be closed after the 5-year follow-up visit of the last patient enrolled into the trial. There will be an interim analysis after the 1-year follow-up visit of the last enrolled patient which includes the evaluation of the primary endpoint and the secondary endpoints.

Table I: Summary of the study parameters

\begin{tabular}{|c|c|c|c|c|c|c|c|c|}
\hline & Preop. & $\begin{array}{c}\text { Discharge } \\
7 \text { - I0 days } \\
\text { postop. }\end{array}$ & $\begin{array}{c}\text { Follow-up } \\
3 \\
\text { months }\end{array}$ & $\begin{array}{l}\text { Follow-up } \\
12 \text { months }\end{array}$ & $\begin{array}{l}\text { Follow-up } \\
2 \text { years }\end{array}$ & $\begin{array}{l}\text { Follow-up } \\
3 \text { years }\end{array}$ & $\begin{array}{c}\text { Follow-up } \\
4 \text { years }\end{array}$ & $\begin{array}{c}\text { Follow-up } \\
5 \text { years }\end{array}$ \\
\hline Clinical examination & $\mathbf{x}$ & & $\mathbf{x}$ & $\mathbf{x}$ & & & & $\mathbf{x}$ \\
\hline Contact by phone & & & & & $\mathbf{x}$ & $\mathbf{x}$ & $\mathbf{x}$ & \\
\hline Metal ion concentrations in plasma & $\mathbf{x}$ & & & $\mathbf{x}$ & & & & $\mathbf{x}$ \\
\hline Testing for hypersensitivity & $\mathbf{x}$ & & & & & & & $\mathbf{x}$ \\
\hline Knee Society score & $\mathbf{x}$ & & $\mathbf{x}$ & $\mathbf{x}$ & & & & $\mathbf{x}$ \\
\hline Oxford score & $\mathbf{x}$ & & $\mathbf{x}$ & $\mathbf{x}$ & $\mathbf{x}$ & $\mathbf{x}$ & $\mathbf{x}$ & $\mathbf{x}$ \\
\hline UCLA activity score & $\mathbf{x}$ & & $\mathbf{x}$ & $\mathbf{x}$ & & & & $\mathbf{x}$ \\
\hline SF 36 & $\mathbf{x}$ & & $\mathbf{x}$ & $\mathbf{x}$ & & & & $\mathbf{x}$ \\
\hline AE/SAE & & $\mathbf{x}$ & $\mathbf{x}$ & $\mathbf{x}$ & $\mathbf{x}$ & $\mathbf{x}$ & $\mathbf{x}$ & $\mathbf{x}$ \\
\hline
\end{tabular}




\section{Current Status and Planning}

The study protocol was completed in December 2008. Preparation of all study-related material was finalised until February 2009. After approval from the local Ethics Committee on 26 February 2009, the first patient was recruited on 27 April 2009 and more patients are currently being enrolled at the centre. Assuming an enrolment of 6 to 8 patients per month, recruitment is expected to be completed at the end of 2010.

\section{Discussion}

An "ideal" knee prosthesis would prevent release of any metal ions into the patient's blood and thus protect him/ her from any local or systemic toxic effects, cancer risk or activation of the immune system possibly resulting in hypersensitivity against components of the prosthesis. Although risks of such adverse effects have not been yet conclusively proven, they cannot be excluded. Therefore, reduction of metal ion release through coating of an implant may be an advantage if disadvantages in terms of premature loosening can be avoided. This underscores the need to test these new implants in clinical trials.

\section{Conclusion}

The present trial is a single-centre, prospective randomised trial to evaluate metal ion release of a novel zirconium-coated total knee prosthesis compared to an uncoated implant of the same geometry. It aims to find out whether this coated implant can reduce metal ion release and how both implants compare with respect to adverse events, functional results and quality of live.

\section{Competing interests}

The authors declare that they have no competing interests, although this study is financially supported by Aesculap AG, Germany including the article processing-charge.

\section{Authors' contributions}

JL, GD, AH, KPG and SK designed the trial together. JL wrote the manuscript with contributions from GD, AH, KPG and SK. GD is performing the metal ion analysis. SK is involved as statistician. JL, $\mathrm{AH}$ and $\mathrm{SK}$ are participating actively in the recruitment of the patients. All authors have read and approved this manuscript.

\section{Acknowledgements}

This study is financially supported by Aesculap AG, Germany.

\section{References}

I. BQS Qualitätsreport 2008: Knie-Totalendoprothesen-Erstimplantation. 2008 [http://www.bqs-outcome.de/2008/ergebnisse/ leistungsbereiche/knie tep erst/datengrundlage/0002 Vollst.html].

2. Wapner KL: Implications of metallic corrosion in total knee arthroplasty. Clin Orthop Relat Res 1991:12.

3. Black J: Does corrosion matter? J Bone Joint Surg Br 1988, 70(4):517.
4. Archibeck MJ, Jacobs J], Black J: Alternate bearing surfaces in total joint arthroplasty: biologic considerations. Clin Orthop Relat Res 2000:12.

5. Silva M, Heisel C, Schmalzried TP: Metal-on-metal total hip replacement. Clin Orthop Relat Res 2005, 430(430):53.

6. Tharani R, Dorey FJ, Schmalzried TP: The risk of cancer following total hip or knee arthroplasty. J Bone Joint Surg Am 200I, 83A(5): 774

7. Jacobs JJ, Gilbert JL, Urban RM: Corrosion of metal orthopaedic implants. J Bone Joint Surg Am 1998, 80(2):268.

8. Rae T: The toxicity of metals used in orthopaedic prostheses. An experimental study using cultured human synovial fibroblasts. J Bone Joint Surg Br 198I, 63-B(3):435.

9. Willert HG, Buchhorn GH, Fayyazi A, Flury R, Windler M, Koster G, Lohmann $\mathrm{CH}$ : Metal-on-metal bearings and hypersensitivity in patients with artificial hip joints. A clinical and histomorphological study. J Bone Joint Surg Am 2005, 87(I):28.

10. Thomas $P$, Schuh A, Ring J, Thomsen M: [Orthopedic surgical implants and allergies: joint statement by the implant allergy working group (AK 20) of the DGOOC (German association of orthopedics and orthopedic surgery), DKG (German contact dermatitis research group) and dgaki (German society for allergology and clinical immunology)]. Orthopade 2008, 37(1):75.

II. Rau C, Thomas $P$, Thomsen M: [Metal sensitivity in patients with joint replacement arthroplasties before and after surgery]. Orthopade 2008, 37(2): 102

12. Thomas P: [Allergic reactions to implant materials]. Orthopade 2003, 32(I):60.

13. Freeman MA, Swanson SA, Heath JC: Study of the wear particles produced from cobalt-chromium-molybdenum-manganese total joint replacement prostheses. Ann Rheum Dis 1969, 28(5 Suppl):29.

14. Heath JC, Freeman MA, Swanson SA: Carcinogenic properties of wear particles from prostheses made in cobalt-chromium alloy. Lancet I97I, I(7699):564.

15. Memoli VA, Urban RM, Alroy J, Galante JO: Malignant neoplasms associated with orthopedic implant materials in rats. JOrthop Res 1986, 4(3):346.

16. Visuri T, Pukkala E, Pulkkinen P, Paavolainen P: Decreased cancer risk in patients who have been operated on with total hip and knee arthroplasty for primary osteoarthrosis: a meta-analysis of 6 Nordic cohorts with $\mathbf{7 3 , 0 0 0}$ patients. Acta Orthop Scand 2003, 74(3):351.

17. Paavolainen P, Pukkala E, Pulkkinen P, Visuri T: Cancer incidence after total knee arthroplasty: a nationwide Finnish cohort from 1980 to 1996 involving 9,444 patients. Acta Orthop Scand 1999, 70(6):609.

18. Luetzner J, Krummenauer F, Lengel AM, Ziegler J, Witzleb WC: Serum metal ion exposure after total knee arthroplasty. Clin Orthop Relat Res 2007, 46 I: 136.

19. Ezzet KA, Hermida JC, Colwell CW Jr, D'Lima DD: Oxidized zirconium femoral components reduce polyethylene wear in a knee wear simulator. Clin Orthop Relat Res 2004:120.

20. Spector BM, Ries MD, Bourne RB, Sauer WS, Long M, Hunter G: Wear performance of ultra-high molecular weight polyethylene on oxidized zirconium total knee femoral components. J Bone Joint Surg Am 200I, 83-A(Suppl 2 Pt 2):80.

21. Tsukamoto R, Williams PA, Clarke IC, Pezzotti G, Shoji H, Akagi M, Yamamoto K: Y-TZP zirconia run against highly crosslinked UHMWPE tibial inserts: knee simulator wear and phasetransformation studies. J Biomed Mater Res B Appl Biomater 2008, 86(I): 145 .

22. Tsukamoto R, Chen S, Asano T, Ogino M, Shoji H, Nakamura T, Clarke IC: Improved wear performance with crosslinked UHMWPE and zirconia implants in knee simulation. Acta Orthop 2006, 77(3):505.

23. Gobel F, Ulbricht S, Hein W, Bernstein A: [Radiological mid-term results of total knee arthroplasty with femoral components of different materials]. Z Orthop Unfall 2008, I 46(2): 194

24. Graves S: Australian Orthoaedic Association National Joint Replacement Registry. 2008 [http://www.dmac.adelaide.edu.au/ aoanirr/documents/aoanirrreport 2008.pdf].

25. Reich J, Thomas P, Hovy L, Lindemaier HL, Zeller R, Schwiesau J: Allergy solutions for orthopaedic Knee-Implants. Biomaterialien 2007, 8(2): 109 . 
26. Lugowski SJ, Smith DC, McHugh AD, Van Loon JC: Determination of chromium, cobalt and molybdenum in synovial fluid by GFAAS. J Trace Elem Electrolytes Health Dis 1991, 5(I):23.

27. Prohaska C, Pomazal K, Steffan I: ETAAS method for the determination of $\mathrm{Cd}, \mathrm{Cr}, \mathrm{Cu}, \mathrm{Mn}$ and $\mathrm{Se}$ in blood fractions and whole blood. Fresenius J Anal Chem 2000, 368(6):627.

\section{Pre-publication history}

The pre-publication history for this paper can be accessed here:

http://www.biomedcentral.com/1471-2474/10/128/pre pub

Publish with Bio Med Central and every scientist can read your work free of charge

"BioMed Central will be the most significant development for disseminating the results of biomedical research in our lifetime." Sir Paul Nurse, Cancer Research UK

Your research papers will be:

- available free of charge to the entire biomedical community

- peer reviewed and published immediately upon acceptance

- cited in PubMed and archived on PubMed Central

- yours - you keep the copyright

Submit your manuscript here:

http://www.biomedcentral.com/info/publishing_adv.asp 